IEEE Int. Conference on Micro Electro Mechanical Systems (MEMS'00), Jan. 2000, Miyazaki, Japan

\title{
LONG THROW AND ROTARY OUTPUT ELECTRO-THERMAL ACTUATORS BASED ON BENT-BEAM SUSPENSIONS
}

\author{
J.-S. Park", L.L. Chu, E. Siwapornsathain, A.D. Oliver" ${ }^{*}$, and Y.B. Gianchandani ${ }^{1}$ \\ Department of Electrical and Computer Engineering, University of Wisconsin, Madison, USA \\ JAAN 242900 \\ "Department of Mechanical Engineering, University of Wisconsin, Madison, USA \\ "Electromechanical Engineering Department, Sandia National Laboratories, USA

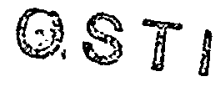

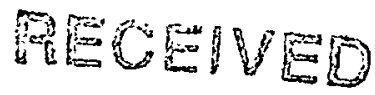

\begin{abstract}
This paper reports on significant advances in electrothermal bent beam acutors. Designs for long throw linear and rotary actutors are desscribed. Silicon $\mathrm{p}++$ devices showed 20-30 $\mu \mathrm{m}$ displacements with $150 \mu \mathrm{N}$ loads at actuation levels of $6-8 \mathrm{~V}$, and $250-300 \mathrm{~mW}$. An electroplated version provided $15 \mu \mathrm{m}$ displacements at 0.8 $V$ and $450 \mathrm{~mW}$. Inchworm type devices are reported that had linear displacements of $100 \mu \mathrm{m}$ with $200 \mu \mathrm{N}$ loads. Refinements in the modeling to account for non-linear thermal expansion coefficents and buckling are also reported.
\end{abstract}

\section{INTRODUCTION}

Although many micromachined actuators have been developed in the past, the options for existing integrated circuit compatible micromachining processes are limited to electrostatic and electrothermal devices. Electrothermal devices consume more power, but provide higher forces and can generally be driven with lower voltages, allowing standard interface electronics to be used. Amongst electro-thermal devices that provide inplane motion, bent beam actuators offer an attractive compromise of displacement, force, scalability and simplicity in design [Guc92, Jon99, Que99].

This paper reports on advances in bent-beam actuators that were previously presented in [Que99]. Refinements in design equations and fabrication techniques are described in section II, along with preliminary results on frequency response and operating life. Designs for long throw and time-sequenced rotary actuators intended for electromechanical firewalls and other secure systems are discussed in section III, along with limits imposed by buckling constraints. Inchworm actuators that reduce power dissipation and increase throw are discussed in section IV.

\section{SIMPLE \& CASCADED BENT-BEAMIS}

The simplest manifestation of bent-beam electrothermal actuators is illustrated in Fig. 1. As an electric current is passed though a V-shaped beam anchored at its ends, thermal expansion caused by joule heating pushes the apex outward. The displacement of the apex is a function of the beam dimensions and slope[Gia96], and can be calculated analytically to within $5 \%$ of finite element analysis (FEA):

$a_{\max }=2 \frac{\tan \theta_{1}}{k} \tan \frac{k L_{1}}{4}-\frac{L_{4}}{2} \tan \theta_{1:} \Delta T=\frac{1}{\alpha \cdot L_{1}}\left(\Delta L^{\prime}+\frac{F L_{1}}{E w_{k} k^{\prime}}\right) ; k=\sqrt{\frac{F}{E I}}$
$L^{\prime}=\frac{\left(\tan \theta_{1}\right)^{2}}{4 k}\left[2 G+k L_{1}+k L_{1} G^{2}+\sin k L_{1}-2 G \cos k L_{1}-G^{2} \sin k L_{1}\right]$

where $G=\tan \left(k L_{l} / 4\right), H=\tanh \left(k L_{l} / 4\right), E=$ Young's modulus, $\alpha=$ expansion coefficient, $h=$ beam thickness, $w=$ beam width, $I=$ moment of inertia of the beam, $L_{1}$ and $\theta_{l}$ are defined in Fig. 1 , and $F$ is an intermediate variable that represents the reaction force along the $x$-axis at the anchors. The comparison to FEA was performed for $500-2000 \mu \mathrm{m}$ lengths, $4-5 \mu \mathrm{m}$ widths and thickness', and $0.025-0.2$ radian bending angles. The peak loading force that can be sustained at the apex, $f_{\text {max }}$, defined as that at which the displacement is forced back to zero. can be calculated analytically within about $10 \%$ :

$$
f_{\max }=d_{\max } K_{y} ; \quad K_{y}=\frac{4 \sin ^{2}\left(\dot{\theta}_{1}\right)+E}{L_{1}}
$$

where $A$ is the cross-sectional area of the beam, and $\theta_{l}{ }^{\prime}$ is the effective bending angle, which may differ from the actual angle as a result of apex displacement, particularly in long beams with a shallow bending angle. Equation (2) accommodates beam elongation, but ignores bending for simplicity. The consistency of this formula with FEA was validated for the same dimensional parameters mentioned above, but over a reduced range of bending angles of 0.05-0.2 radian. (A simpler formula for $f_{m u r}$ described in [Que99] is substantially more pessimistic.)

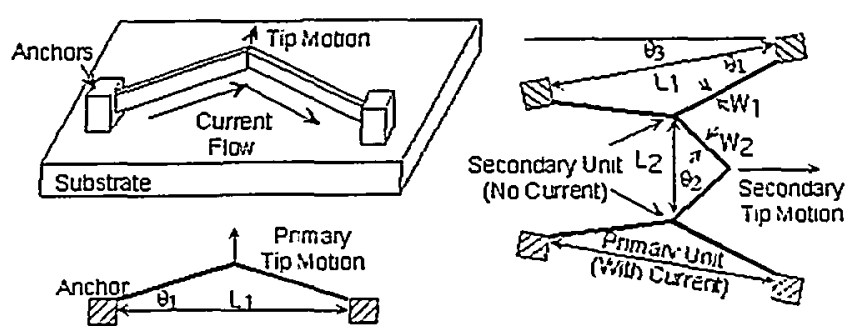

Fig. I The basic unit of the bent-beam thermal actuator (left), and a cascaded device (right).

'Corresponding author: 1+15 Engineering Dr., UW-Madison. 53706-1691. USA: Tel: (608) 262-2233: Fax: 262-1267: yogesh@engr.wisc.edu 
In equation (1), it was assumed that the expansion coefficient of the structural material is not a function of temperature. Although this makes the analytical solution more tractable, it underestimates the displacement by about $30 \%$ for $\mathrm{Si}$ devices. The expansion coefficient of $\mathrm{Si}$ increases from about $2.5 \mathrm{ppm} / \mathrm{K}$ at room temperature to 4 $\mathrm{ppm} / \mathrm{K}$ at $400^{\circ} \mathrm{C}$ [Ko85]. Using an expression for the expansion coefficient that provides a linear fit through these points, displacement and force curves were obtained by non-linear FEA with ANSYSTM (Figs. 2,3).

Besides scaling dimensional parameters, higher forces can be generated by placing these actuators in parallel, and larger displacements can be generated by cascading the actuators [Que99]. For cascaded actuators, if two primary base units are driven by the same power supply, there will be no current sustained by the secondary unit (Fig. 1). Cascaded devices have three to four times larger displacement than simple beams without heating the secondary unit. Heating the secondary unit increases this advantage.

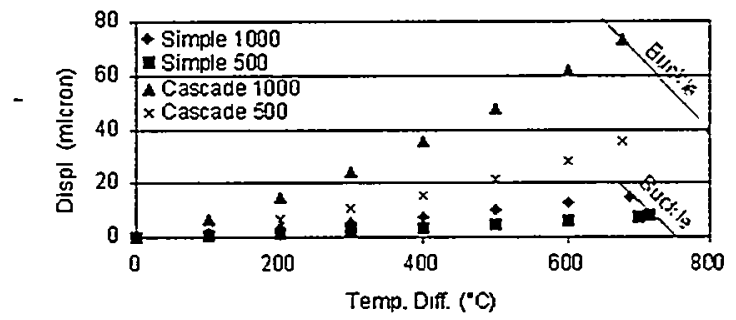

Fig. 2: Non-linear FEA of $\mathrm{Si}$ actuators. Simple: $\mathrm{H}=4.5 \mu \mathrm{m}$. $\mathrm{W}=6 \mu \mathrm{m}, \theta \mathrm{l}=0.2 \mathrm{rad}, \mathrm{L}=500 / 1000 \mu \mathrm{m}$. Cascaded: $\mathrm{H}=4.5 \mu \mathrm{m}$. $\mathrm{W} 1=6 \mu \mathrm{m} . \quad \mathrm{W} 2=4 \mu \mathrm{m}, \quad \theta 1=0.1 \quad \mathrm{rad}, \quad \theta 2=0.2 \quad \mathrm{rad}$. $\mathrm{Ll}=\mathrm{L} 2=500 / 1000 \mu \mathrm{m}$, secondary unit was unheated.

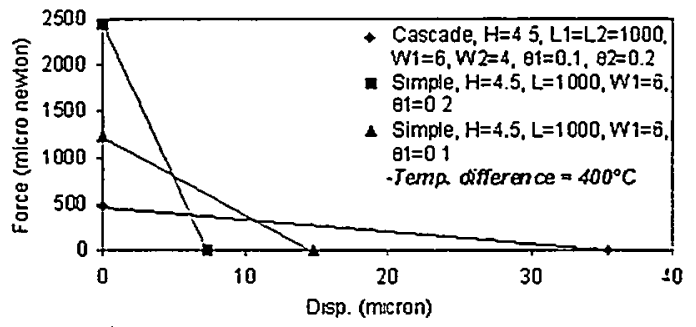

Fig. 3: FEA load lines of Si actuators at $400^{\circ} \mathrm{C}$. In the cascaded device, the secondary unit was inheated.

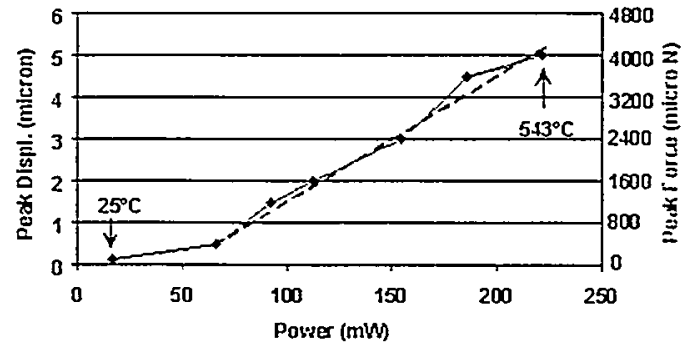

Fig. 4: Measured $d_{\text {max }}$ of a simple $\mathrm{p}^{++}$Si bent-beam actuator (left axis), and the corresponding $f_{\max }$ calculated for the input power level (right axis). $\mathrm{L}=800 \mu \mathrm{m}, \mathrm{W}=10 \mu \mathrm{m}, \mathrm{H}=3.7 \mu \mathrm{m}$. and $\theta=0.2$ rad. The peak drive was $13 \mathrm{~V}$. at $221 \mathrm{~mW}$.

\section{Temperature, Power, and Choice of Materials}

Polysilicon, $\mathrm{p}+\mathrm{Si}$, and electroplated $\mathrm{Ni}$ are commonly used structural materials for MEMS, and are good candidates for electro-thermal actuators [Que99]. The expansion coefficient of $\mathrm{Si}$ is $2.5-5 \mathrm{ppm} / \mathrm{K}$ over the temperatures of interest, while it is $12-16 \mathrm{ppm} / \mathrm{K}$ for electroplated $\mathrm{Ni}$. Although this can result in larger displacement for $\mathrm{Ni}$ devices, the offset displacement changes with the ambient temperature because of its expansion mismatch with the substrate, which is typically $\mathrm{Si}$ or a type of glass that is expansion matched to $\mathrm{Si}$. Moreover, while polysilicon devices can be operated to about $600^{\circ} \mathrm{C}$ (above which in situ annealing can be a threat), and $\mathrm{p}+\mathrm{Si}$ structures can be operated even hotter, the upper limit for $\mathrm{Ni}$ structures is about $350^{\circ} \mathrm{C}$, beyond which an irreversible darkening of the structure is observed to occur (possibly due to oxidation), along with degradation of the actuation stroke.

Since the thermal isolation of most microstructures with respect to the substrate and the ambient is 1.000 $10,000 \mathrm{~K} / W$ [Gia97]. maintaining a temperature of $600^{\circ} \mathrm{C}$ requires only $60-600 \mathrm{~mW}$ of power [Que99]. Moreover. the actuation voltages are in the range of $5-25 \mathrm{~V}$. permitting the use of standard electronic interfaces that are generally inadequate for electrostatic actuators.

\section{Fabrication}

Preliminary fabrication results were obtained using polysilicon, $\mathrm{p}^{+} \mathrm{Si}$, and electroplated $\mathrm{Ni}$ separately as structural materials using the processes described in [Que99]. The only significant modification was in the release sequence used for electroplated $\mathrm{Ni}$ microstructures. For these, after stripping the mold and wet etching the seed and sacrificial layers in $\mathrm{HCl} . \mathrm{Cr}$ etchant, and $\mathrm{HF}$ respectively, the $\mathrm{Ni}$ was selectively plated with $\approx 500 \AA \mathrm{Au}$ by immersing for $10 \mathrm{~min}$. in an electroless plating solution (Alfa Aesar $\# 42307$ ) at $60^{\circ} \mathrm{C}$. This is followed by a coating of self-assembled monolayers, as reported previously. The Au coating improves the hydrophobicity of the surface, thereby reducing stiction. More importantly, it provides an inert chemical coating to the $\mathrm{Ni}$ actuators, elevating the operating limit from $\approx 350^{\circ} \mathrm{C}$ to $\approx 450^{\circ} \mathrm{C}$. This increases the peak displacements achievable with $\mathrm{Ni}$ devices.

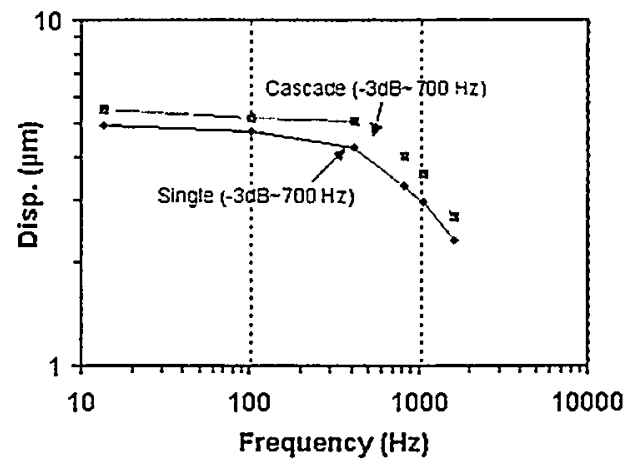




\section{DISCLAIMER}

This report was prepared as an account of work sponsored by an agency of the United States Government. Neither the United States Government nor any agency thereof, nor any of their employees, make any warranty, express or implied, or assumes any legal liability or responsibility for the accuracy, completeness, or usefulness of any information, apparatus, product, or process disclosed, or represents that its use would not infringe privately owned rights. Reference herein to any specific commercial product, process, or service by trade name, trademark, manufacturer, or otherwise does not necessarily constitute or imply its endorsement, recommendation, or favoring by the United States Government or any agency thereof. The views and opinions of authors expressed herein do not necessarily state or reflect those of the United States Government or any agency thereof. 


\section{DISCLAIMER}

Portions of this document may be illegible in electronic image products. Images are produced from the best available original document. 
Fig. 5: Measured frequency response of $\mathrm{p}^{++} \mathrm{Si}$ thermal actuators with dimensions as in Fig. 7. The drive signals were $10 \mathrm{~V}$ square waves for the single (cascaded) device.

\section{Measurements of Displacement, Force, Speed, Reliability}

Measurements of a fabricated basic $\mathrm{p}^{++} \mathrm{Si}$ actuator are plotted in Fig. 4. Verniers built into the devices were used to make peak deflection measurements. The peak force is calculated from the peak deflection. The approximate linearity of the response indicates that conductive heat loss dominates, as expected. The average temperature of the actuator was estimated from the increase in its resistance as the drive power was increased. Piezoresistance can account for no more than $15 \%$ of the resistance change, and is generally much lower.

Thermal actuators are generally slower than electrostatic ones because the thermal time constants involved are longer than the electrical and mechanical time constants for most microstructures. However. there is a common misperception about the drive frequencies that are possible. Preliminary tests for both simple and cascaded devices indicate that non-resonant actuation frequencies in excess of $1 \mathrm{KHz}$ are reasonable (Fig. 5). This is possible because of the very small thermal mass of these structures. It is worth noting that the heat (and current) in these structures can be confined to selected bent beams as discussed in [Que99], while others serve purely as motion amplifiers. This can help to maintain short thermal time constants even for larger and more complex mechanisms.

Preliminary tests were conducted to assess the reliability of simple bent-beam actuators. A device with the dimensions described in Fig. 7 was exercised with a $6 \mathrm{~V}, 300 \mathrm{~Hz}$ square wave for a total of 6 million cycles. There was no degradation in the amplitude of the motion to the extent that could be determined by the integrated vernier. However, it is reasonable to expect that device lifetime is related to drive amplitude. Additional studies are being conducted to determine the operation limits.

In all the measurements made on the preliminary test structures, no cross-talk was ever observed between devices - even those in close proximity to each other. This indicates that the temperature increase is localized to the activated device. The relatively small thermal mass of these devices and the relatively high thermal conductivity and thermal mass of the substrate are likely contributing factors. This' indicates that standard microsensor packaging technology is adequate for thermal actuators.

\section{ROTARY ACTUATORS}

Rotary actuators are used to drive mechanical discriminators for electromechanical firewalls and other secure systems [Gar98]. In order to serve these applications, the rotary actuator must drive a $100 \mu \mathrm{m}$ diameter gear with a stall torque of at least $500 \mathrm{pN}-\mathrm{m}$. In the past, orthogonally arranged pairs of comb-driven electrostatic actuators have been used to drive the output gear. Since the loading force is small, the motivation for electro-thermal actuation in this context is largely the lower actuation voltages which permit the used of standard circuit interfaces.

The rectilinear stroke of the bent-beam actuator can be converted into rotary motion of a gear by impact drive [Lee92], or the translation of a linear rack which is engaged with the output gear. The former is difficult to implement with continuous loading forces, susceptible to friction problems, and the repeated impact raises concerns of lifetime and reliability. The latter is relatively slow, and requires very large linear displacement. An attractive compromise is offered by two orthogonal cascaded drives providing the 2-axis motion needed to rotate the gear (Fig. 6). This approach provides continuous motion, fast response, and potentially high reliability.

With the drive pin is located $15 \mu \mathrm{m}$ from the center of the gear, the target displacement for the actuators is about $30 \mu \mathrm{m}$. The $500 \mathrm{pN}-\mathrm{m}$ stall torque requirement is satisfied if output force at this displacement exceeds 33 $\mu \mathrm{N}$. Since $33 \mu \mathrm{N}$ is much lower than a typical $f_{\max }$ (Figs. 3,4 ), it is assumed that $d_{\text {target }} \approx d_{\text {max }}$.

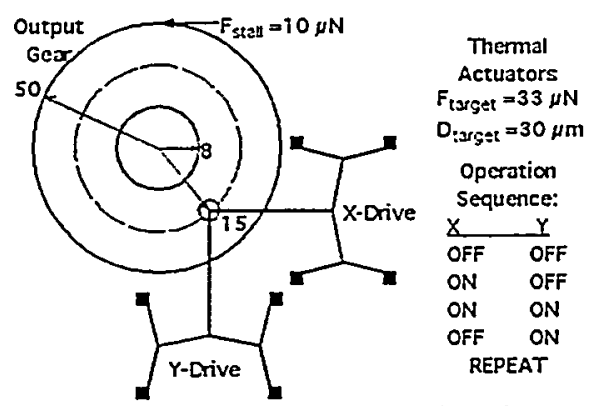

Fig. 6: Schematic of a rotary actuator based on orthogonal cascaded bent-beam elements for a gear of $50 \mu \mathrm{m}$ radius.

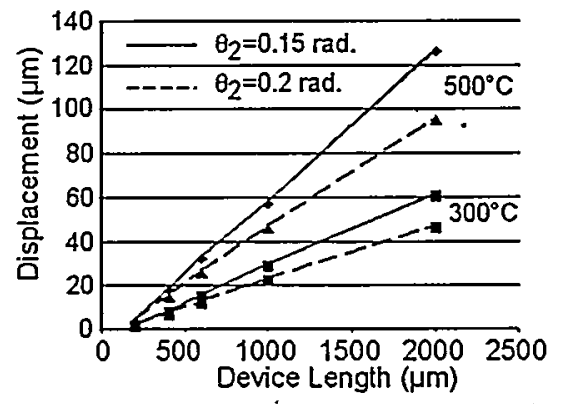

Fig. 7: Non-linear FEA of an orthogonal pair of cascaded $\mathrm{Si}$ actuators with one axis is actuated. Dimensions: $\mathrm{Wl}=6 \mu \mathrm{m}$. $\mathrm{W} 2=\mathrm{W} 3=4 \mu \mathrm{m}, \theta \mathrm{l}=0 . \mathrm{Irad} ., \mathrm{H}=4.5 \mu \mathrm{m}$, and $\mathrm{Ll}=\mathrm{L} 2=\mathrm{L} 3$. 

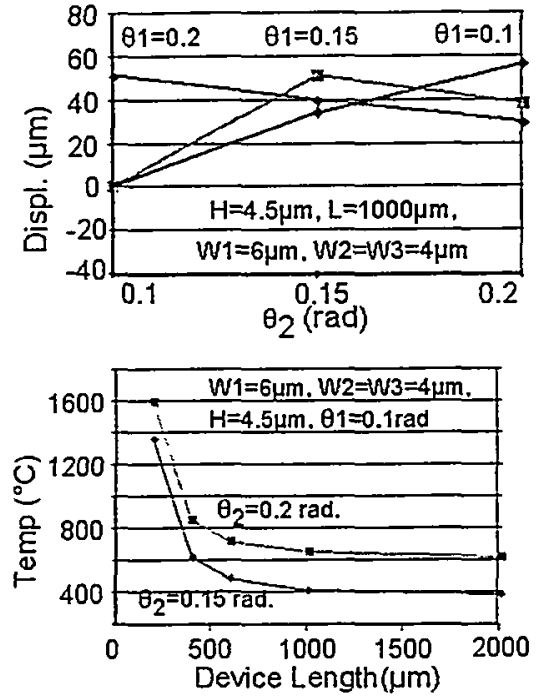

Fig. 8: (a-upper) Lateral displacements that can be achieved before lateral buckling occurs; (b-lower) The maximum average operating temperature that can be achieved before vertical buckling occurs. FEA of orthogonal pairs, with $40 \mu \mathrm{N}$ external loading force, and non-linear expansion of $\mathrm{Si}$.

The FEA orthogonal pairs of identical cascaded actuators shows that a $30 \mu \mathrm{m}$ stroke can be achieved by $\mathrm{Si}$ actuators with suspension lengths of about $700 \mu \mathrm{m}$ at $<500^{\circ} \mathrm{C}$ (Fig. 7). The FEA model included both the $\mathrm{X}$ and $\mathrm{Y}$ actuators, and accounted for the loading of each upon the other (which is larger than $33 \mu \mathrm{N}$ output load). However, although shallower bending angles promise higher displacement, they have a greater propensity for out-of-plane buckling.

\section{Vertical Buckling}

For many designs, vertical buckling can be the limiting factor for maximum displacement, output force, and drive temperature. For cascaded structures and other complex shapes. FEA is necessary to examine vertical stability. Using the geometrical model, boundary conditions, material properties, and an external loading force of $40 \mu \mathrm{N}$ (max. loading force of $33 \mu \mathrm{N}+7 \mu \mathrm{N}$ safety margin), the static solver is first executed. Following this, the buckling solver is executed, specifying a single degree of freedom, as desired for vertical or lateral buckling. This approach (using element Beam4) matched analytical formulas for buckling straight beam under various boundary conditions within $5 \%$.

The predictions for buckling temperature obtained by FEA are pessimistic because only one degree of freedom is specified. In reality, lateral deflections that occur in normal operation of the device reduce the propensity for vertical buckling. Lateral buckling presents a problem in addition to vertical buckling. When lateral buckling occurs, the V-shape of base unit in a cascaded becomes inverted, rendering the device inoperational. Figure $8 \mathrm{a}$ shows the lateral buckling results, plotting the maximum lateral deflection that can be achieved before a cascaded actuator buckles laterally. Figures 2 and $8 \mathrm{~b}$ show the temperature at which an actuator will buckle vertically. Bending angles of $\theta 1=0.1 \mathrm{rad}$. and $\theta 2=0.2 \mathrm{rad}$. provide the best compromise for both lateral and vertical buckling. Process variations such as increased structural thickness longitudinal corrugations in the structural material can help to further increase the vertical buckling temperature.

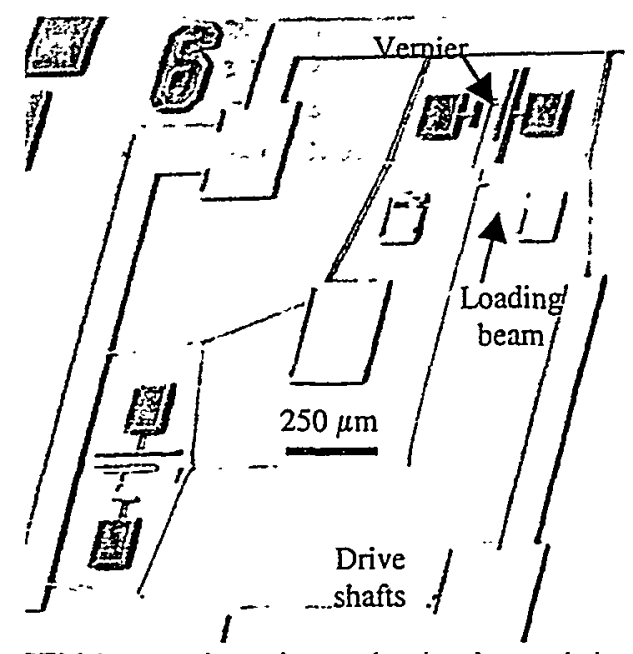

Fig. 9: SEM image of a orthogonal pair of cascaded actuators fabricated from $\mathrm{p}+\mathrm{Si}$ using the dissolved wafer process.
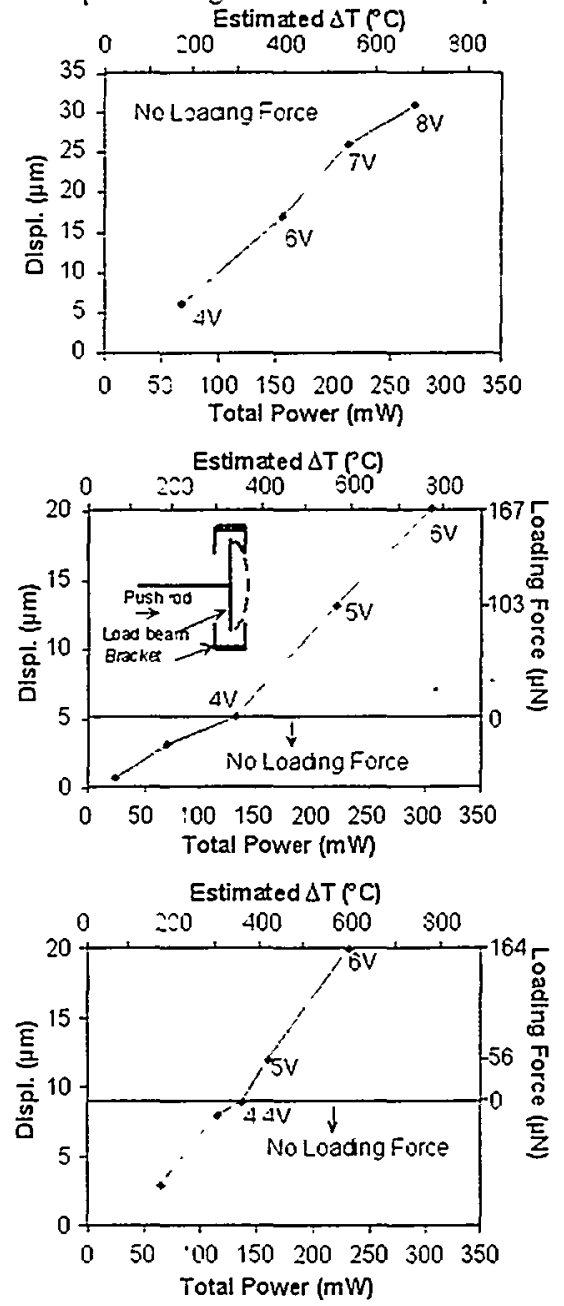
Fig. 10: (a: top-c: bottom) Measurements $\mathrm{p}+\mathrm{Si}$ rotary actuators $\mathrm{R} 3, \mathrm{R} 5$, and R6, respectively (Table I). In all cases the $\mathrm{X}$ and $\mathrm{Y}$ actuators were activated together.

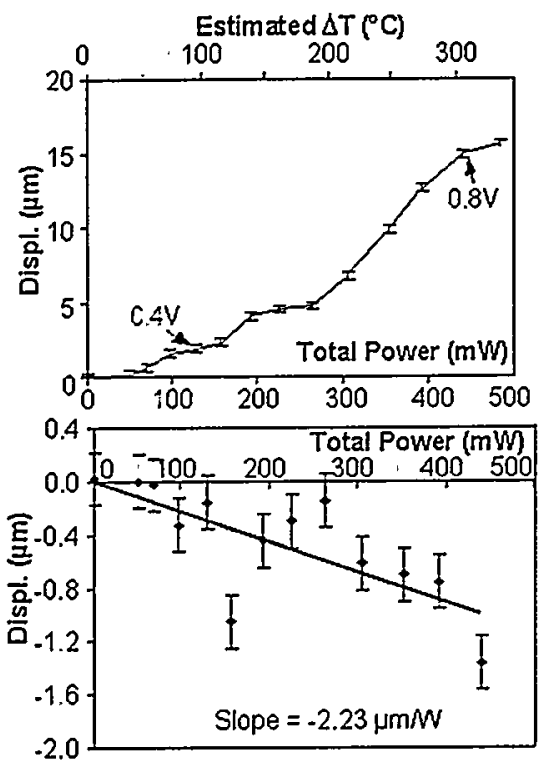

Fig. 11: Measured results of electroplated rotary actuator RJ3 (Table I) with only one axis actuated: (a-upper) the forward displacement of the actuated axis; and (b-lower) a small backward displacement along the orthogonal axis.

Table I: Dimensions of rotary output actuators in $\mu \mathrm{m}$ and radians. $L 1=L 2=L 3, \theta 1=0.1 \mathrm{rad}$, and $\theta 2=0.2 \mathrm{rad}$. $L_{3} 3$ is the length of the push rods. All devices are $6.5 \mu \mathrm{m}$ thick, except $\mathrm{J} 3$, which is $11.0 \mu \mathrm{m}$ thick. The load beam is $250 \mu \mathrm{m}$ long, and $3.15 \mu \mathrm{m}$ wide; $\mathrm{D}=$ diagonal placement; $\mathrm{Y}=$ placement across the $Y$ actuator drive shaft alone.

\begin{tabular}{|c|c|c|c|c|c|}
\hline Name & L & W1 & W2 & $\theta 3$ & Load \\
\hline R3 & 1000 & 4.3 & 2.3 & 0 & none \\
\hline R5 & 500 & 5.5 & 5.5 & 0 & D \\
\hline R6 & 500 & 5.2 & 3.2 & 0.2 & Y \\
\hline RJ3 & 500 & 5.7 & 6.7 & 0.2 & none \\
\hline
\end{tabular}

\section{Measured Results}

Operation of the rotary actuators was validated by fabricating them in both electroplated $\mathrm{Ni}$ and $\mathrm{p}+\mathrm{Si}$ using abbreviated processes which provided a single structural layer. This precluded the fabrication of gears because a second structural layer would then be necessary to cap (vertically constrain) the gear, and a third one to provide a linkage with clearance above it. The loading effect of the gear on the actuator was emulated by a loading beam constrained by brackets at each end. The loading beam was attached transversely to the drive shaft along each axis and/or at the location of the gear (Fig. 9).

A number of different designs were fabricated and tested. The measured results are plotted in Fig. 10 and 11, whereas the dimensional parameters for these devices are listed in Table 1. For devices R3 and RJ3, there was no loading force applied, whereas for devices R5 and R6, loading force was applied only for displacements higher than a certain threshold, which was the displacement necessary for the loading beam to come, into contact with its bracket constraint. Beyond this point, the loading force increased with displacement, which was measured using integrated verniers. The $\mathrm{Si}$ devices showed displacements of $20-30 \mu \mathrm{m}$ with beam lengths of 500$1000 \mu \mathrm{m}$, total power levels $<300 \mu \mathrm{mW}$, and peak actuation voltages in the $6-8 \mathrm{~V}$ range.

\section{INCHWORMS}

In the preceding section, bent beam actuators with 1-2 levels of cascading were shown to generate rectilinear displacements of several tens of microns. For applications that require an order of magnitude more displacement, alternate approaches are necessary. Since rotary actuators are available, one option is to use gear trains coupled to a linear rack. Another option, which is potentially less susceptible to frictional wear, is to use inchworms. Pairs of opposing bent-beam actuators are pulsed to grip and shift a central shank, which is cantilevered on a flexible suspension (Fig. 12). The sidewall of the shank and the mating surfaces of the actuators are corrugated to reduce their reliance on friction. The actuators effectively work as a split cascade: when actuated, the individual actuators move forward until they touch the shank, at which point they effectively form a single actuator with an additional level of cascading, which further amplifies the motion. Another pair of opposing actuators, located at a different point along the shank, can be actively operated out of phase with the first to provide complementary motion. Alternatively, the second pair can serve as a passive lock that prevents the shank form being pulled back once it has been displaced. This results in tremendous power savings when a displacement must be held for extended time intervals. It also increases the operating life of the device. As shown in Fig. 12, the passive lock can also be designed to retract when actuated. The peak displacement of the shank is reached when the pull-back force from the extension of the spring matches the output force from the active pair of actuators. This is in contrast to impactdriven slider mechanisms, which rely on friction and do not develop high forces [Pai99, Kia98].

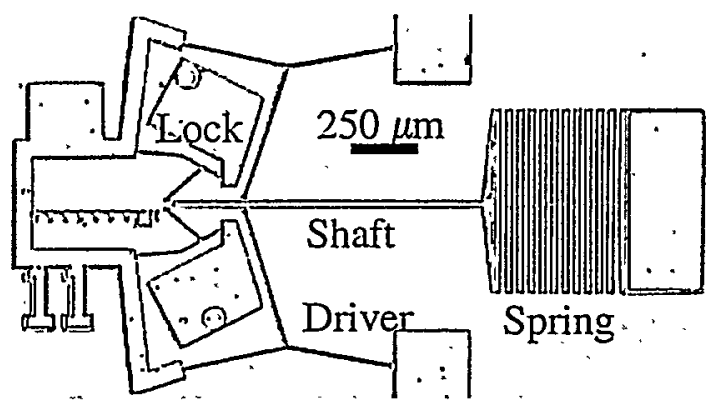




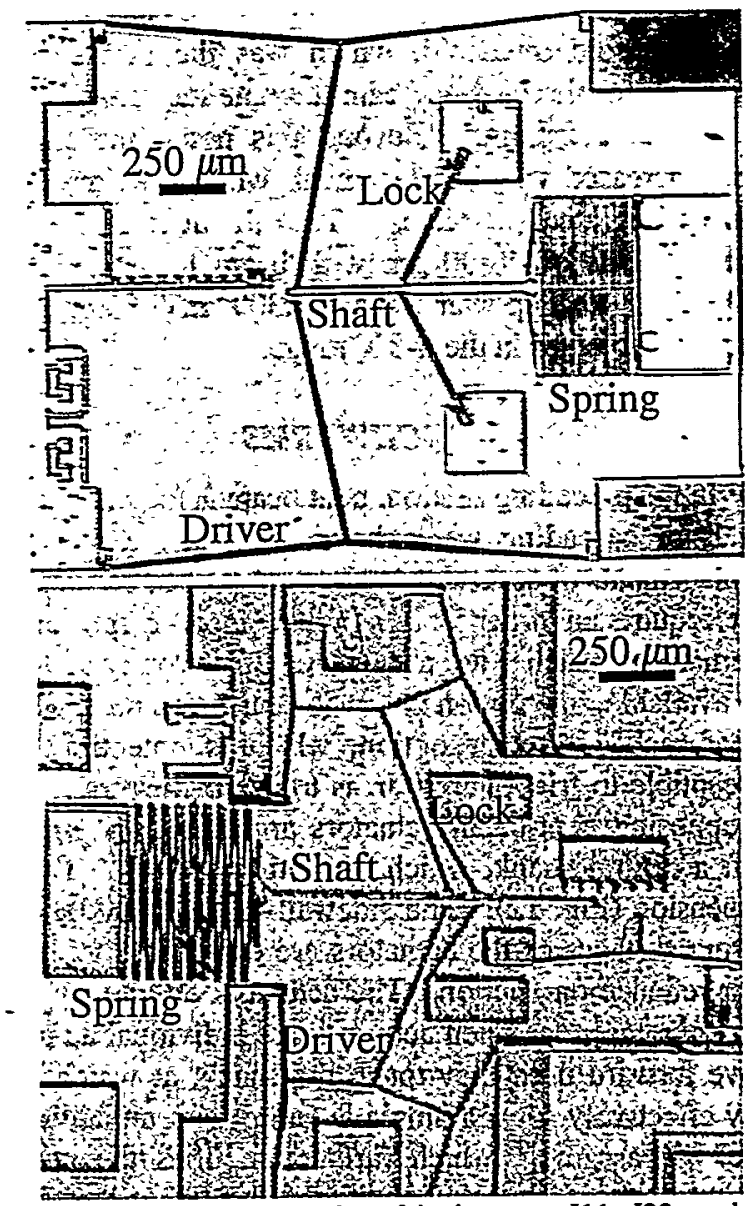

Fig. 12: Optical micrographs of inchworms I11, I33, and IL1 (Table II). IL1 shows a latched displacement in this image. Designs not shown are $\mathrm{I100}$, which is similar to $\mathrm{I} 33$ but has a different spring, and ILA, which is similar to IL 4 but $40 \%$ longer $\mathrm{L} 1$ and L2, and releasable locks.

Table II: Measurement results of electroplated Ni inchworms listing device thickness, peak displacement achieved. calculated stiffness of the spring at the base of the shank, and actuation method (for which $\mathrm{P}=$ voltage pulse).

\begin{tabular}{|c|c|c|c|c|}
\hline Device & $\begin{array}{c}\text { Thick- } \\
\text { ness }(\mu \mathrm{m})\end{array}$ & $\begin{array}{c}\text { Displ. } \\
(\mu \mathrm{m})\end{array}$ & $\begin{array}{c}\mathrm{K}_{\text {sp }} \\
(\mathrm{N} / \mathrm{m})\end{array}$ & $\begin{array}{c}\text { Actuation } \\
\text { Method }\end{array}$ \\
\hline I11 & 9.0 & 40 & 0.51 & DC: $1 \mathrm{~V}$ \\
\hline I33 & 14.0 & $\mathbf{5 3}$ & 0.895 & P: $24 \mathrm{~ms} .0 .8 \mathrm{~V}$ \\
\hline I100 & 8.4 & $\mathbf{3 2}$ & 5.33 & DC: $1 \mathrm{~V}$ \\
\hline ILI & 11.0 & $\mathbf{1 0 0}$ & 1.96 & P: $24 \mathrm{~ms} .1 .2 \mathrm{~V}$ \\
\hline IL4 & 9.8 & $\mathbf{5 0}$ & 1.73 & P: $38 \mathrm{~ms} .1 .2 \mathrm{~V}$ \\
\hline
\end{tabular}

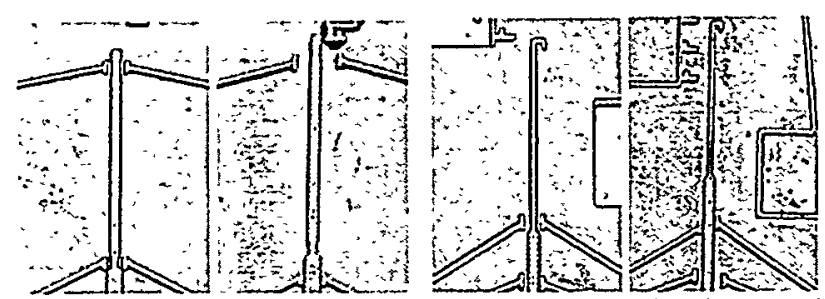

Fig. 13: Optical micrographs comparing unactuated and actuated inchworms: (a-left) I33 with $56 \mu \mathrm{m}$ displacement; (b-right) ILI with $100 \mu \mathrm{m}$ displacement.

\section{Measured Results}

A number of different inchworms were designed and fabricated using a single structural layer of electroplated Ni. Preliminary tests were performed on the devices shown in Fig. 12. Designs I11, I33, and I100 use pairs of simple actuators that effectively have a one-level cascade when they touch the shaft, whereas designs LI and L4 have a two-level cascade after they touch the shaft. Designs III and ILA have releasable passive locks, whereas the other have unreleasable ones.

The preliminary measurement results are summarized on Table II. Locked displacements of upto $100 \mu \mathrm{m}$ were achieved using DC $(\leq 1 \mathrm{~V}, 250 \mathrm{~mA})$ or pulsed $(\leq 1.2 \mathrm{~V}$, $\leq 600 \mathrm{~mA}$ ) actuation (Figs. 12, 13). The best pulse widths were empirically found to be in the $20-40 \mathrm{~ms}$ range. These are probably determined by the thermomechanical time constants of the microstructure.

The stiffness of the spring located at the base of each inchworm shank can be estimated from measured dimensional parameters by the formula $K_{s p}=192 E I_{s} /\left(N L_{s}^{3}\right)$, where $E$ is the Young's modulus of the electroplated $\mathrm{Ni}$, estimated to be $150 \mathrm{GPa}$; $I_{s}$ is the moment of inertia of the spring beam, which is a half loop; $L_{s}$ is the length of the half loop, and $N$ is the total number of them present. This formula assumes fixed-fixed boundary conditions, which match observations of deformed springs. Using this, the peak forces generated in devices I100 and ILl were calculated as $171 \mu \mathrm{N}$ and $196 \mu \mathrm{N}$, respectively (Table II). In reality, the maximum displacement achievable by the inchworm is limited not only by spring stiffness, but also by out-of-plane deformation of the actuators or the shaft. This are caused by stress gradients in the structural material and by the sloping sidewalls of the shank and the mating surfaces of the actuators. The peak forces generated by the inchworms, therefore, are expected to be higher than those estimated above.

\section{CONCLUSION}

This effort has examined several issues pertaining to the performance and application of $\mathrm{p}+\mathrm{Si}$ and $\mathrm{Ni}$ bent beam actuators that were introduced in [Que99]. Issues addressed for simple and cascaded actuators include: (i) refinements in modeling such the use of non-linear expansion coefficients and the evaluation of lateral and vertical buckling limits; (ii) fabrication improvements that increase by about $100^{\circ} \mathrm{C}$ the peak operating temperatures for $\mathrm{Ni}$ devices by electroless $\mathrm{Au}$ plating; (iii) measurements of operating frequency which indicate a $3 \mathrm{db}$ bandwidth of $700 \mathrm{~Hz}$ for both simple and cascaded $\mathrm{p}+$ Si structures. Orthogonally placed pairs of cascaded thermal actuators were applied to rotary drives. Fabricated $\mathrm{p}+$ Si devices with $500-1000 \mu \mathrm{m}$ beam lengths and $6.5 \mu \mathrm{m}$ thickness showed 20-30 $\mu \mathrm{m}$ diagonal displacement with $>150 \mu \mathrm{N}$ loading at actuation levels of 6-8 V, and $250-300 \mathrm{~mW}$. An electroplated version with $500 \mu \mathrm{m}$ beam lengths and $11 \mu \mathrm{m}$ thickness provided 15 $\mu \mathrm{m}$ displacement at $0.8 \mathrm{~V}, 450 \mathrm{~mW}$. When a single axis 
is actuated, there is a backward displacement of about 1 $\mu \mathrm{m}$ along complementary axis. Opposing pairs of simple and cascaded actuators were applied to inchworms. Several designs were fabricated with electroplated $\mathrm{Ni}$, and tested with $\mathrm{DC}$ and pulsed actuation schemes. Devices with $500-1500 \mu \mathrm{m}$ beam lengths and 8-14 $\mu \mathrm{m}$ thickness provided displacements of up to $100 \mu \mathrm{m}$ against estimated loading forces of up to $196 \mu \mathrm{N}$. Overall, these efforts have demonstrated that bent-beam electro-thermal actuators can be used to generate displacements and forces in the $100 \mu \mathrm{m}, 100 \mu \mathrm{N}$ range, and can be used in energy efficient ways for a variety of applications.

Acknowledgements: The authors gratefully acknowledge Sandia National Labs. for supporting the work on rotary actuators. Sandia is a multiprogram laboratory operated by Sandia Corporation, a

Lockheed Martin Company, for the United States Department of Energy under contract DE-AC04-94AL85000.

[Gar98] E.J. Garcia, "Micro-flex mirror and instability actuation technique," IEEE Conf. on Micro Electro Mechanical Systems, Heidelberg, p. 470-5, Jan. 1998

[Gia96] Y. Gianchandani, K. Najafi, "Bent-Beam Strain Sensors," IEEE J. Microelectromechanical Sys. 5(1), pp. 52-8, March 3/96

[Gia97] Y.B. Gianchandani, K. Najafi, "Scanning Thermal Profilers with Integrated Sensing and Actuation," IEEE Trans. Electron - Devices, 44(11), pp. 1857-68, Nov. '97

[Guc92] H. Guckel, J. Klein, T. Christenson, K. Skrobis, M. Laudon, E.G. Lovell, "Thermo-magnetic metal flexure actuators," SolidState Sensor \& Actuator Workshop, (Hilton Head), p. 73-5, 6/92

[Jon99] J. Jonsmann, O. Sigmund, S. Bouwstra, "Compliant ElectroThermal Microactuators," IEEE Conf. on Micro Electro Mechanical Systems, Orlando, pp. 588-592, '99

[Kia98] M.-H. Kiang, O. Solgaard, K.Y. Lau, R.S. Muller, "Electrostatic combdrive-actuated micromirrors for laser-beam scanning and positioning," IEEE J. Micro-electromechanical Sys, 7(1), pp. 27-37, Mar. '98

[K085] W.H. Ko, J.T. Suminto, G.J. Yeh, "Bonding techniques for microsensors," Micromachining and Micropackaging of Sensors, 1985, Elsevier Science Publishers, and Microsensors, Ed. R.S. Muller et al, 1990, IEEE Press

[Lee92] A.P. Lee A.P. Pisano, "Polysilicon angular vibromotors," IEEE J. of Microelectromechanical Sys, 1(2), pp. 70-76, 6/92

[Pai99] M. Pai, N.C. Tien, "Current-controlled bi-directional electrothermally actuated vibromotor," IEEE Transducers '99. Jun. '99, Sendai,, pp. 1764-7

[Que99] L. Que, J.-S. Park, Y.B. Gianchandani, "Bent-Beam ElectroThermal Actuators for High Force Applications," IEEE Conf. on Micro Electro Mechanical Systems, Jan. 1999, Orlando 